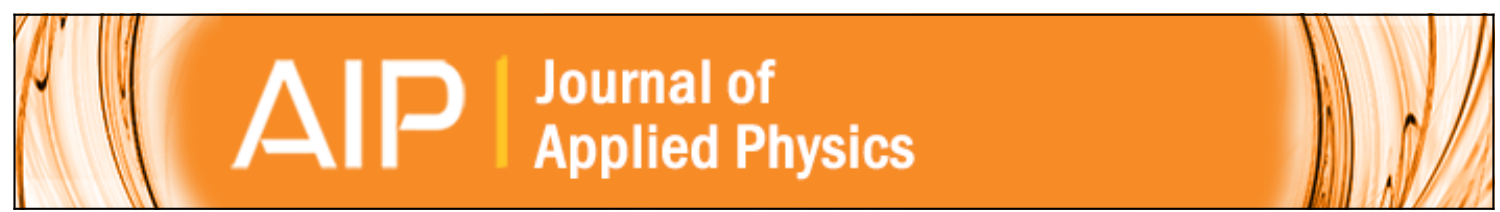

Relationships between the plasma environment and the composition and optical properties of plasmapolymerized thin films produced in rf discharges of $\mathrm{C} 2 \mathrm{H} 2 \mathrm{SF} 6$ mixtures

Steven F. Durrant, Rogério P. Mota, and Mário A. Bica de Moraes

Citation: Journal of Applied Physics 71, 448 (1992); doi: 10.1063/1.350676

View online: http://dx.doi.org/10.1063/1.350676

View Table of Contents: http://scitation.aip.org/content/aip/journal/jap/71/1?ver=pdfcov

Published by the AIP Publishing

$\underset{\text { Aoubloning }}{A}$ Re-register for Table of Content Alerts

Create a profile.

Sign up today! 


\title{
Relationships between the plasma environment and the composition and optical properties of plasma-polymerized thin films produced in rf discharges of $\mathrm{C}_{2} \mathrm{H}_{2}-\mathrm{SF}_{6}$ mixtures
}

\author{
Steven F. Durrant, Rogério P. Mota ${ }^{a}{ }^{a}$ and Mário A. Bica de Moraes \\ Instituto de Fisica "Gleb Wataghin", Universidade Estadual de Campinas, CEP 13081, Caixa Postal \\ 6165, Campinas, Săo Paulo, Brazil
}

(Received 23 July 1991; accepted for publication 30 September 1991)

\begin{abstract}
Polymer films were grown in if discharges containing different proportions of $\mathrm{C}_{2} \mathrm{H}_{2}$ and $\mathrm{SF}_{6}$. Quantitative optical emission spectrometry (actinometry) was used to follow the trends in the plasma concentrations of the species $\mathrm{H}$ and $\mathrm{F}$, and more tentatively, of $\mathrm{CH}, \mathrm{CF}$, and $\mathrm{CF}_{2}$, as a function of the feed composition. Infrared spectroscopy revealed the density of $\mathrm{CH}$ and $\mathrm{CF}$ bonds in the deposited material. As the partial pressure of $\mathrm{SF}_{6}$ in the feed was increased, the degree of fluorination of the polymer also rose. The form of the dependency of the deposition rate on the proportion of $\mathrm{SF}_{6}$ in the feed was in good qualitative agreement with the activated growth model. From transmission ultraviolet visible spectroscopy data the refractive index and the absorption coefficient of the polymers were calculated as a function of the deposition parameters. Since the optical gap depended to some extent upon the degree of fluorination, it could, within limits, be determined by a suitable choice of the proportion of $\mathrm{SF}_{6}$ in the feed. A qualitative explanation of this relationship is given.
\end{abstract}

\section{INTRODUCTION}

Plasma polymerization is a process of importance for the production of novel materials: Often polymers possessing specific optical or electrical properties and showing good adhesion to the substrate may be so produced. ${ }^{1-4} \mathrm{Al}-$ though applications of plasma polymerization are of growing technological importance, the processes that take place in the plasma are poorly understood. One way of studying these interactions is optical emission spectrometry using actinometry. This powerful and widely used method, for determining trends in the concentrations of particular species within the plasma as a function of plasma parameters, was developed just over a decade ago by Coburn and Chen. ${ }^{5,6}$ It has the great advantage of being, for practical purposes, nonintrusive.

In the actinometric method, the concentration of the species of interest $[X]$, is related to the concentration of the actinometer $[A]$ by the equation

$$
[X] /[A] \propto I_{X} / I_{A},
$$

where $I_{X}$ and $I_{A}$ are the optical emission intensities from species $X$ and $A$, respectively. It should be remembered, however, that the applicability of Eq. (1) is limited to species for which the following conditions hold: (i) direct electron-impact excitation is by far the most important excitation process from the ground state to the emitting state; (ii) the excited states decay only by photon emission; (iii) the ratio of the excitation efficiencies to the states responsible for the emissions in species $X$ and $A$ remains constant as the plasma conditions are varied.

Actinometric optical emission spectrometry has been successfully applied, inter alia, to the study of $F$ in

\footnotetext{
a) Also with: Departamento de Física e Química, FEG, Universidade Estadual Paulista, Guaratinguetá, CEP 12500, São Paulo, Brazil.
}

$\mathrm{CF}_{4}-\mathrm{O}_{2}$ plasmas; $;, 7,8 \mathrm{~F}, \mathrm{CF}$, and $\mathrm{CF}_{2}$ in $\mathrm{CF}_{4}-\mathrm{H}_{2}$, $\mathrm{CF}_{4}-\mathrm{C}_{2} \mathrm{~F}_{4}, \mathrm{C}_{2} \mathrm{~F}_{6}-\mathrm{H}_{2}$, and $\mathrm{C}_{3} \mathrm{H}_{8}-\mathrm{H}_{2}$ plasmas; ${ }^{9} \mathrm{~F}, \mathrm{O}, \mathrm{CO}, \mathrm{CF}$, and $\mathrm{CF}_{2}$ in $\mathrm{C}_{2} \mathrm{~F}_{6}-\mathrm{O}_{2}$ plasmas; ${ }^{10}$ and $\mathrm{Br}$ in $\mathrm{Br}_{2}$ plasmas. ${ }^{11}$ Good reviews of the technique have also been published. ${ }^{12,13}$

In this work, acetylene-sulfur hexafluoride gas mixtures have been polymerized in a rf plasma system. Species of interest such as $\mathrm{CH}, \mathrm{CF}, \mathrm{CF}_{2}, \mathrm{H}$, and $\mathrm{F}$ have been investigated by actinometry, and the relative concentration data so obtained, related to the composition of the sample as determined by transmission infrared spectroscopy (IRS). This allowed the determination of the number density of $\mathrm{CH}$ and $\mathrm{CF}$ bonds, in films grown in plasmas containing various proportions of $\mathrm{C}_{2} \mathrm{H}_{2}$ and $\mathrm{SF}_{6}$. By transmission ultraviolet-visible spectroscopy (UVS) some optical parameters, namely the refractive index and the absorption coefficient, were also studied as a function of the deposition parameters. It has thus been possible to show that films containing a controlled amount of fluorine may be produced, the proportion increasing with the percentage of $\mathrm{SF}_{6}$ in the plasma feed.

\section{EXPERIMENT}

The experimental arrangement is shown in Fig. 1. The Pyrex reactor consisted of a tube of diameter $7.5 \mathrm{~cm}$ and length $25 \mathrm{~cm}$ which opened into a bell structure of diameter $19 \mathrm{~cm}$ and height $27 \mathrm{~cm}$. Two external aluminium ring electrodes with a separation of $7 \mathrm{~cm}$ allowed the application of if power to generate the plasma within the tube. The rf generator ( $120 \mathrm{MHz}, 40 \mathrm{~W}$ ) was connected to the ring electrodes through the impedance matching circuit and the throughline wattmeter. Both the generator and matching unit were of in-house design; the wattmeter (model WL 2300) was supplied by Linear Equipamentos Eletronicos Ltda, Brazil. 


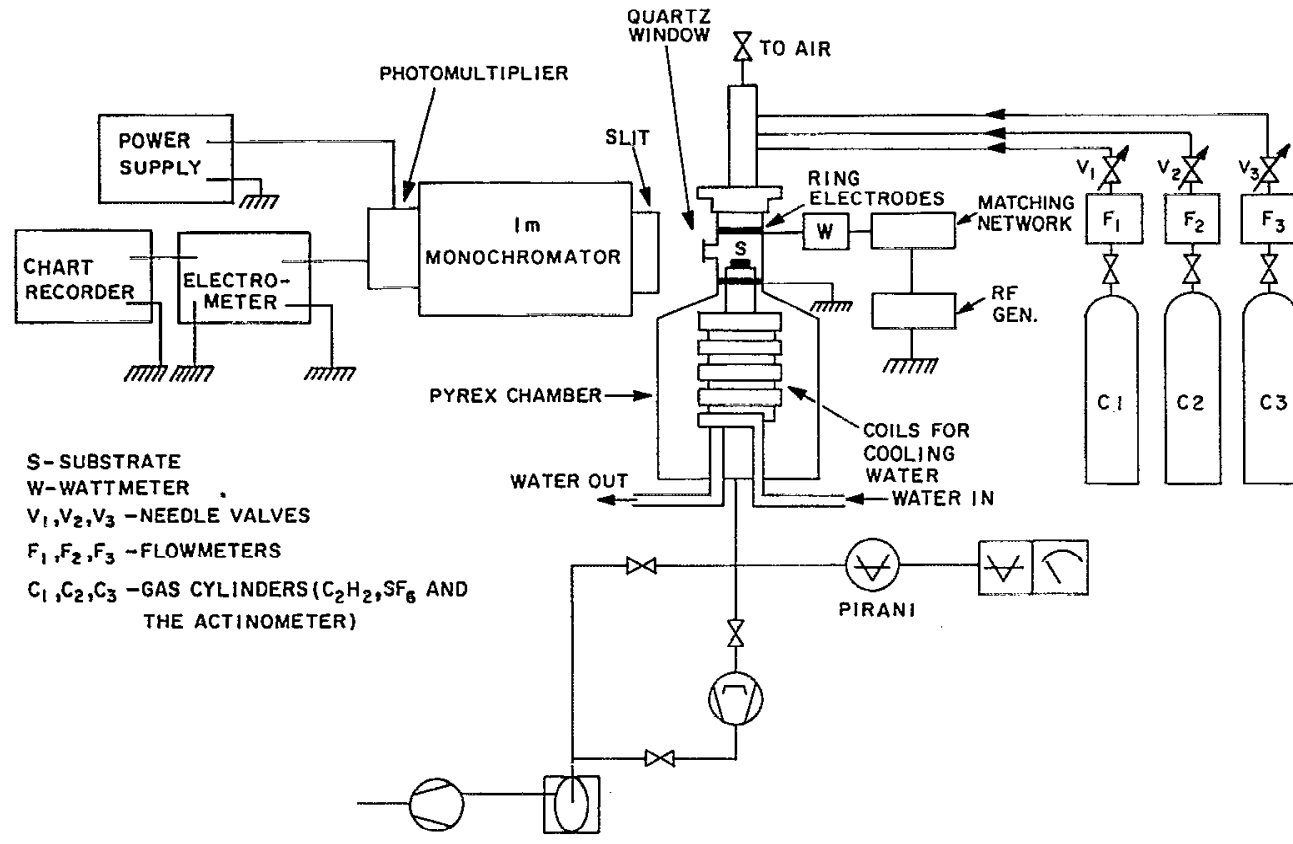

FIG. 1. The if plasma polymerization system and optical emission spectrometry equipment.

Since the chamber walls accumulated a film of polymer, a removable glass inner sleeve was used to allow easy cleaning. Gases were fed to the chamber from cylinders via the needle valves V1 to V3 and flowmeters F1 to F3. Acetylene (of minimum purity $99.5 \%$ ), $\mathrm{SF}_{6}$ ( $99.9 \%$ pure), and the actinometers $\mathrm{N}_{2}, \mathrm{Ar}$, and $\mathrm{He}$ were supplied by White Martins, Brazil. The actinometers were of at least $99.99 \%$ purity.

A dynamic equilibrium at a constant total pressure of 0.2 mbar, as measured by a Pirani gauge, was established in the absence of a discharge by an Edwards two-stage rotary pump of nominal pumping rate $12 \mathrm{~m}^{3} \mathrm{~h}^{-1}$. The presence of the discharge obviously alters the system pressure, but this pressure could not be measured using the Pirani gauge due to of interference. However, the partial pressure of $\mathrm{SF}_{6}$ in the feed, as measured in the absence of the discharge, does serve as a controllable variable for the production of fluorinated films. Only one actinometer was used on any one occasion, at a partial pressure of $\frac{1}{20}$ of the total.

An applied power of $12 \mathrm{~W}$ was maintained throughout since this was found to give films exhibiting good adhesion to the substrate. Samples for analysis by IRS and UVS were prepared on substrates of $\mathrm{KBr}$ and quartz, respectively. An infrared spectrophotometer (Jasco, model IR 700) was used to obtain absorption spectra. Ultravioletvisible analyses were performed using a Perkin Elmer model lambda 9 spectrophotometer.

Deposition rates were calculated from the thicknesses of films grown for known periods of time. Film thickness was itself determined by producing a well-defined film outline using a mask, evaporating an aluminium coating onto the film, and then measuring the step height by an optical interferometer (Varian, A-scope).

The optical spectrometry system is also shown in Fig. 1. Light from the plasma escaped from the chamber via a quartz window and reached the slit of a 1-m focal length monochromator spectrometer (Spex Industries, model 14300 ). The output of the uv-visible photomultiplier (Hammamatsu Photonics K.K., model R943-02) was monitored on the chart recorder (Hewlett Packard, model 17 501A) via an electrometer (Keithley Instruments, model $610 \mathrm{CR}$ ).

\section{RESULTS AND DISCUSSION}

\section{A. Actlnometry}

Some of the species that are expected to play an important role in film deposition $\left(\mathrm{CF}, \mathrm{CF}_{2}, \mathrm{CH}, \mathrm{F}\right.$, and $\mathrm{H}$ ) were easily observed in the discharge. However, $\mathrm{CF}_{3}$ and other massive radicals, such as $\mathrm{SF}_{x}$ were not detected. (Commonly observed $\mathrm{CF}_{3}$ emissions lie below the minimum wavelength detectable with our system). Table I lists the species of interest, the emission wavelength, and the respective excitation thresholds.

Use of several actinometers with different excitation thresholds gives some hints as to the behavior of the electron density and the electron energy distribution as a func-

TABLE I. Spectral data of species of interest

\begin{tabular}{lccc}
\hline Species & System & $\lambda(\mathrm{nm})$ & $\begin{array}{c}\text { Threshold energy } \\
(\mathrm{eV})\end{array}$ \\
\hline $\mathrm{CF}$ & $B^{2} \Delta-X^{2} \Pi$ & 207.6 & $\sim 6$ \\
$\mathrm{CF}{ }_{2}$ & $\widetilde{A}^{1} B_{1}-\widetilde{X}^{1} A_{1}$ & 276.0 & $\sim 4.5$ \\
$\mathrm{CH}$ & $A^{2} \Delta-X^{2} \Pi$ & 431.4 & $<11$ \\
$\mathrm{H}$ & $2 p^{2} P_{3 / 2^{0}-3 d^{2} D_{3 / 2}}$ & 656.3 & 12.09 \\
$\mathrm{~F}$ & $3 s^{2} P-3 p^{2} P$ & 703.7 & 14.74 \\
$\mathrm{~N}_{2}$ & $C^{3} \Pi_{u}-B^{3} \Pi_{2}$ & 337.1 & 11.2 \\
$\mathrm{Ar}$ & $4 p^{1}\left(\frac{1}{2}\right)-4 s^{1}\left(\frac{1}{2}\right)$ & 750.3 & 13.47 \\
$\mathrm{He}$ & $3 p^{3} P-2 s^{3} S$ & 388.9 & 23.01 \\
\hline \hline
\end{tabular}




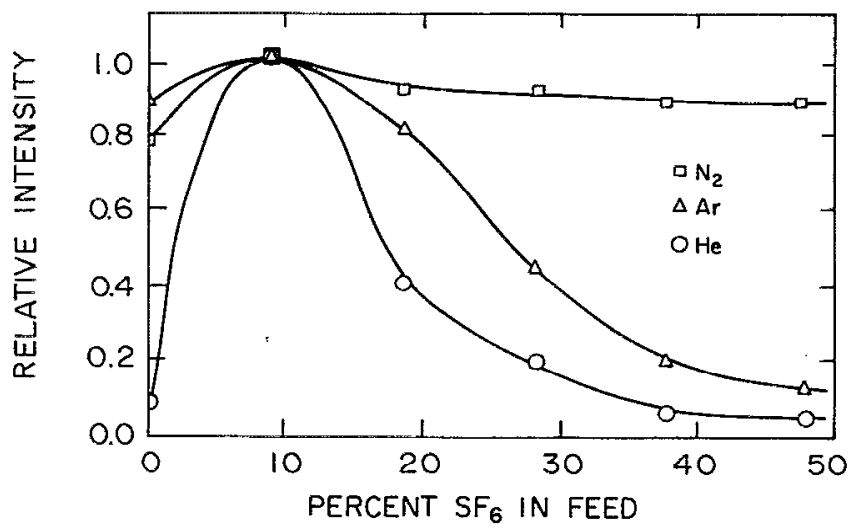

FIG. 2. Relative intensity of the actinometers ( $\mathrm{He}, \mathrm{Ar}, \mathrm{N}_{2}$ ) as a function of the percent $\mathrm{SF}_{6}$ in the feed.

tion of a plasma parameter; in this case the partial pressure of $\mathrm{SF}_{6}$ in the feed expressed as a percentage of the total pressure. Figure 2 shows the intensity of the actinometers $\mathrm{He}, \mathrm{Ar}$, and $\mathrm{N}_{2}$ as a function of this parameter. The plots are normalized to one at their common maximum at about $9 \% \mathrm{SF}_{6}$.

For any species $X$, which is excited by direct electron impact excitation and decays only by photon emission, the emission intensity $I_{X}$ is given by ${ }^{12}$

$$
I_{X}=k n_{X} \eta_{X}=k^{\prime} n_{X} \int_{0}^{\infty} \sigma(E) N_{e}(E) d E,
$$

where $n_{X}$ is the ground-state concentration of the species, $\eta_{X}$ the excitation efficiency, $N_{e} d E=E^{1 / 2} F_{e}(E) d E$, and represents the number of electrons per unit volume of the plasma in the energy range $d E, F_{e}(E)$ is the electron distribution function (EDF), $\sigma(E)$ is the excitation cross section to the state responsible for the emission, and $k$ and $k^{\prime}$ are constants. It is thus apparent that since the actinometer concentrations remain constant in the discharge, variations in the emission intensities of the actinometers can be attributed to modifications in the EDF. As the ratio of $\mathrm{C}_{2} \mathrm{H}_{2}$ to $\mathrm{SF}_{6}$ changes, modifications in both the plasma electron density and the average electron energy are to be expected, either of which will alter the EDF.

Inspection of Fig. 2 shows that for a given increase in the proportion of $\mathrm{SF}_{6}$ in the feed, dissimilar relative changes in the intensities of the three actinometers are observed. Thus, consideration of changes in the electron density alone is not sufficient to explain the behavior of the intensity plots of Fig. 2: Because the excitation threshold for $\mathrm{He}$ is high $(23 \mathrm{eV})$, the wide variations in the $\mathrm{He}$ emission intensity can be attributed mainly to changes in the number of high-energy electrons, i.e., those having energies of about $23 \mathrm{eV}$ or more. Furthermore, the intensity curve for $\mathrm{He}$ in Fig. 2 indicates that the EDF is greater than in pure $\mathrm{SF}_{6}$ feeds, except for proportions of $\mathrm{SF}_{6}$ above about $35 \%$.

For electron energies well above the excitation threshold, the excitation cross section is usually accepted to be a slowly varying function of $E$. This implies from Eq. (2), that the relative emission intensity can be taken as roughly

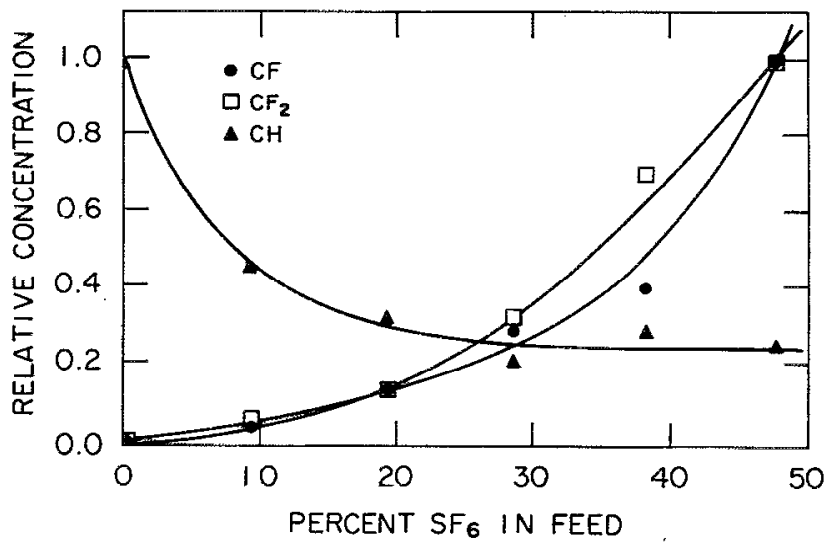

FIG. 3. Relative concentration as a function of the percent $\mathrm{SF}_{6}$ in the feed for the species $\mathrm{CF}, \mathrm{CF}_{2}$, and $\mathrm{CH}$. Nitrogen used as an actinometer at $5 \%$.

proportional to the total electron density, irrespective of the average electron energy. Since the excitation threshold for nitrogen is relatively low $(11 \mathrm{eV})$, the small variation in the $\mathrm{N}_{2}$ emission intensity (as compared with the large variation in the $\mathrm{He}$ emission intensity) is compatible with changes in the average electron energy of $\mathrm{C}_{2} \mathrm{H}_{2}-\mathrm{SF}_{6}$ plasmas already having a relatively large density of fast electrons.

In order to obtain trends in the concentrations of the $\mathrm{CH}, \mathrm{CF}$, and $\mathrm{CF}_{2}$ species in the discharge, $\mathrm{N}_{2}$ was employed as the actinometric gas. We justify the use of nitrogen on the fact that $\mathrm{CH}, \mathrm{CF}$, and $\mathrm{CF}_{2}$ have thresholds for emission of less than $11 \mathrm{eV}$. Presumably, therefore, as for $\mathrm{N}_{2}$, the cross-section contributions to the variations in their excitation efficiencies are small. This allows us to write

$$
\frac{\eta_{X}}{\eta_{\mathrm{N}_{2}}} \approx \text { const, }
$$

where $\eta_{X}$ and $\eta_{\mathrm{N}_{2}}$ are the excitation efficiencies of the species of interest and $\mathrm{N}_{2}$ respectively, and consequently, to apply the basic equation of actinometry [Eq. (1)].

The behavior of the concentrations of the species $\mathrm{CH}$, $\mathrm{CF}$, and $\mathrm{CF}_{2}$ with increasing $\mathrm{SF}_{6}$ in the discharge is shown in Fig. 3. As might be expected, $\mathrm{CF}$ and $\mathrm{CF}_{2}$ concentrations increase, and $\mathrm{CH}$ levels decrease with additional $\mathrm{SF}_{6}$. These trends reflect the increase in the supply of fluorine and the decrease in that of hydrogen and carbon.

The closeness of the excitation thresholds for $\mathrm{H}$ (12.09 $\mathrm{eV})$ and $\mathrm{F}(14.74 \mathrm{eV})$ to that of $\mathrm{Ar}(13.47 \mathrm{eV})$ justifies the use of the latter as an actinometer in the determination of the trends in the concentrations of $\mathrm{H}$ and $\mathrm{F}$. The similarity between the excitation thresholds for a given species and actinometric gas has been used by several investigators ${ }^{6,14}$ as a criterion for the application of Eq. (1).

Fig. 4 shows the concentration of atomic hydrogen and fluorine in the plasma as a function of the $\mathrm{SF}_{6}$ percentage in the $\mathrm{C}_{2} \mathrm{H}_{2}-\mathrm{SF}_{6}$ mixtures. Addition of $\mathrm{SF}_{6}$ strongly enhances the atomic hydrogen concentration in the plasma. For an $\mathrm{SF}_{6}$ percentage in the feed of nearly $25 \%$, the hydrogen concentration rises by almost one order of magni- 


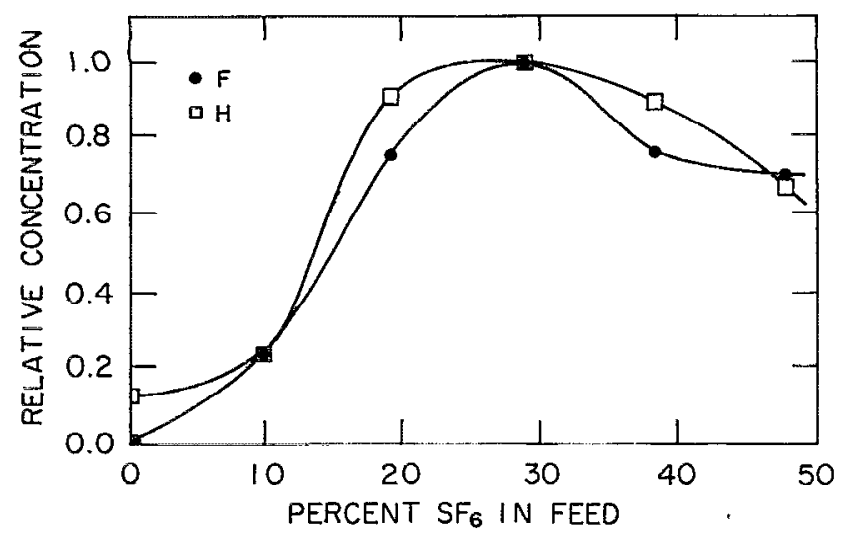

FIG. 4. Relative concentration as a function of the percent $\mathrm{SF}_{6}$ in the feed for the species $\mathrm{H}$ and $\mathrm{F}$. Argon used as an actinometer at $5 \%$.

tude with respect to its value in pure $\mathrm{C}_{2} \mathrm{H}_{2}$ plasmas. The relative plasma fluorine concentration exhibits an increase up to about $30 \% \mathrm{SF}_{6}$ and declines a little thereafter. Up to the maximum, the fluorine concentration increases faster than the supply of fluorine from $\mathrm{SF}_{6} ;$; e.g., for a change in the $\mathrm{SF}_{6}$ percentage from $10 \%$ to $20 \%$ the atomic fluorine concentration changes by a factor of about 4 .

The behavior of the hydrogen and fluorine concentrations probably results from complex reactions in the gas phase and on the inner surfaces of the reactor. Furthermore, these reactions take place in a plasma environment in which the electron distribution function varies according to the percentage of $\mathrm{SF}_{6}$ in the feed. In spite of the large variations in the plasma composition, the similar behavior of the $\mathrm{F}$ and $\mathrm{H}$ concentration plots may be interpreted primarily as a consequence of the electron distribution function. The increasing portion of these curves is compatible with our previous interpretation that addition of $\mathrm{SF}_{6}$ increases the EDF. The decline in the concentration of $\mathrm{H}$ and $\mathrm{F}$ appears to be a consequence of the decline of the $\mathrm{EDF}$ at high levels of $\mathrm{SF}_{6}$. It should be noted that atomic $\mathrm{H}$ and $\mathrm{F}$ may be produced both by electron impact with species in the gas phase and on the growing polymer surface. Energetic electrons are known to break bonds of hydrogen and fluorine bound to surfaces. ${ }^{15}$ In our reactor, a relatively large polymer surface could interact with the plasma since deposition of the polymer films usually took place not only on the substrate and substrate holder but also on the reactor walls. Thus the polymer surface contribution to the presence of atomic $\mathbf{H}$ and $\mathrm{F}$ in the gas phase should not be disregarded.

A plasma containing $\mathrm{SF}_{6}$ might also be expected to contain a small amount of atomic sulfur, and indeed we have detected $S$ optically $(469.4 \mathrm{~nm})$. In addition, since all the species $\mathrm{SF}_{x}(x=1-6)$ are probably present in pure $\mathrm{SF}_{6}$ discharges, ${ }^{16}$ they may also be expected here. In particular, the reaction

$$
\mathrm{SF}_{6}+e \rightarrow \mathrm{SF}_{2}+4 \mathrm{~F}+e
$$

may play an important part in the plasma chemistry. ${ }^{17}$ The species $\mathrm{S}_{2}$ and $\mathrm{S}_{2} \mathrm{~F}^{+}$have also been detected in $\mathrm{SF}_{6}$

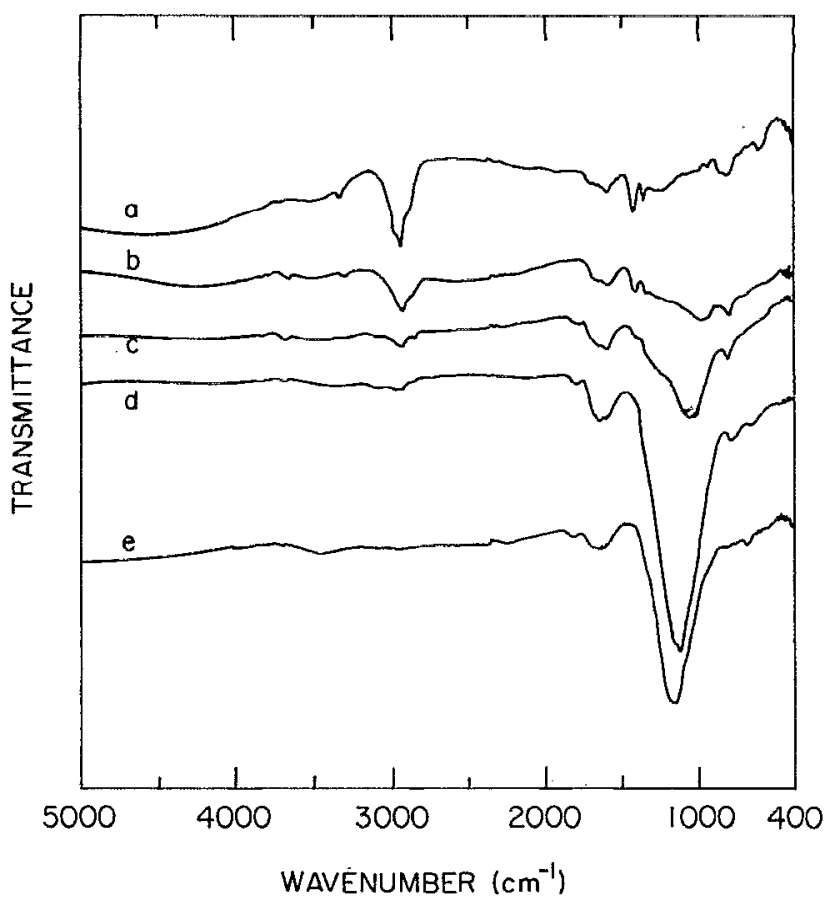

FIG. 5. Infrared spectra of polymers grown at (a) $0 \%$, (b) $10 \%$, (c) $20 \%$, (d) $30 \%$, and (e) $40 \% \mathrm{SF}_{6}$ in the feed.

plasmas. ${ }^{18}$ Almost certainly, the overall reaction scheme is highly complex.

\section{B. Film composition}

Films for analysis by infrared spectroscopy were grown at proportions of $\mathrm{SF}_{6}$ in the feed of $0 \%, 10 \%, 20 \%$, $30 \%$ and $40 \%$. No actinometric gas was used, but otherwise plasma conditions were identical to those used for the actinometric studies. Figure 5 shows the infrared spectra thus obtained. The absorption bands due to $\mathrm{C}-\mathrm{H}$ bonds are prominent in the spectrum of the film prepared with $100 \% \mathrm{C}_{2} \mathrm{H}_{2}$ in the feed. The strong absorption at 2930 $\mathrm{cm}^{-1}$ arises from symmetrical and asymmetrical stretching modes in $\mathrm{CH}_{2}$ and $\mathrm{CH}_{3}$ groups. Asymmetrical and symmetrical bending modes in $\mathrm{CH}_{3}$ groups give rise to the bands at 1440 and $1375 \mathrm{~cm}^{-1}$, respectively. Other absorptions are due to $\mathrm{C}=\mathrm{C}\left(1625 \mathrm{~cm}^{-1}\right)$, and to hydroxyl $\left(3500 \mathrm{~cm}^{-1}\right)$ and carbonyl $\left(1700 \mathrm{~cm}^{-1}\right)$ groups. It should be noted that plasma polymers may contain a high concentration of free radicals, trapped from the plasma. ${ }^{19}$ Therefore, the existence of hydroxyl and carbonyl groups is probably a consequence of the reactions between the free radicals and ambient oxygen. ${ }^{20}$ The appearance of the wide band between 900 and $1500 \mathrm{~cm}^{-1}$ in the spectra of the films prepared with $\mathrm{SF}_{6}$ in the feed implies the existence of $\mathrm{C}-\mathrm{F}$ bonds in $\mathrm{CF}_{2}$ and $\mathrm{CF}_{3}$ groups. Simple inspection of the CF band at $900-1500 \mathrm{~cm}^{-1}$ and the $\mathrm{CH}$ band at 2930 $\mathrm{cm}^{-1}$ immediately shows that the $\mathrm{C}-\mathrm{F}$ and $\mathrm{C}-\mathrm{H}$ bonds coexist in different proportions in the polymer films.

A quantitative evaluation of the relative $\mathrm{C}-\mathrm{F}$ and $\mathrm{C}-\mathrm{H}$ bond densities can be made, respectively, from the integrated absorption of the bands at 2930 and at 900-1500 


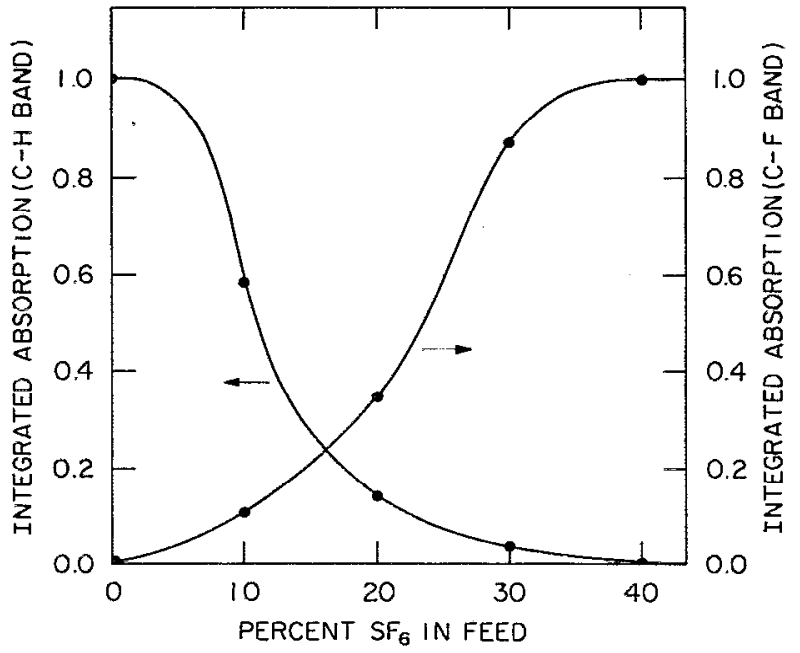

FIG. 6. Integrated absorptions of the $\mathrm{CF}$ and $\mathrm{CH}$ bands (from the ir spectra of Fig. 5) expressed as a function of the percent $\mathrm{SF}_{6}$ in the feed.

$\mathrm{cm}^{-1}$. Figure 6 shows the integrated absorptions of the $\mathrm{C}-\mathrm{F}$ and $\mathrm{C}-\mathrm{H}$ bonds calculated by the method of Lanford and Rand, ${ }^{21}$ as a function of the percentage of $\mathrm{SF}_{6}$ in the feed. As the proportion of $\mathrm{SF}_{6}$ in the discharge is raised, the bound fluorine content increases while the (bound) hydrogen content decreases. The decreasing slope of the fluorine content plot for high $\mathrm{SF}_{6}$ levels indicates that a maximum for the possible fluorine content of the films is reached at $\mathrm{SF}_{6}$ percentages around $40 \%$. Interestingly enough, at this point, the hydrogen content becomes nearly zero.

Since sulfur atoms or sulfur-containing species are present in the discharge, the question arises as to whether sulfur is attached to the polymer films. Carbon-sulfur and hydrogen-sulfur absorption bands occur at wavelengths smaller than $1000 \mathrm{~cm}^{-1}$, have low intensity, and are not observed in the spectra of Fig. 5. However, some sulfur attachment is expected, particularly in polymers grown in discharges having relatively high $\mathrm{SF}_{6}$ concentrations.

\section{Correlation between the actinometric, ir, and deposition rate data}

A comparison of the data of Figs. 6 and 3 reveals a strong correlation between the fluorine content of the films and the concentrations of the $\mathrm{CF}_{x}(x=1,2)$ species in the plasma; both increase with increasing $\mathrm{SF}_{6}$ levels. In fact, the species $\mathrm{CF}_{x}$ have already been recognized as the true monomers, or "building blocks," for polymers formed in glow discharges. ${ }^{9}$ The correlation between the fluorine content of the films and $\mathrm{CF}_{x}$ concentrations in the plasma strongly suggests that gas-phase reactions between carbon and fluorine-containing species play an important role in film formation. This, however, does not exclude the possibility of other reactions taking place at the polymer surface, leading to fluorine attachment.

It should be noted that for $\mathrm{SF}_{6}$ levels near $40 \%$, a relatively high concentration of the species $\mathrm{CH}$ is still ob-

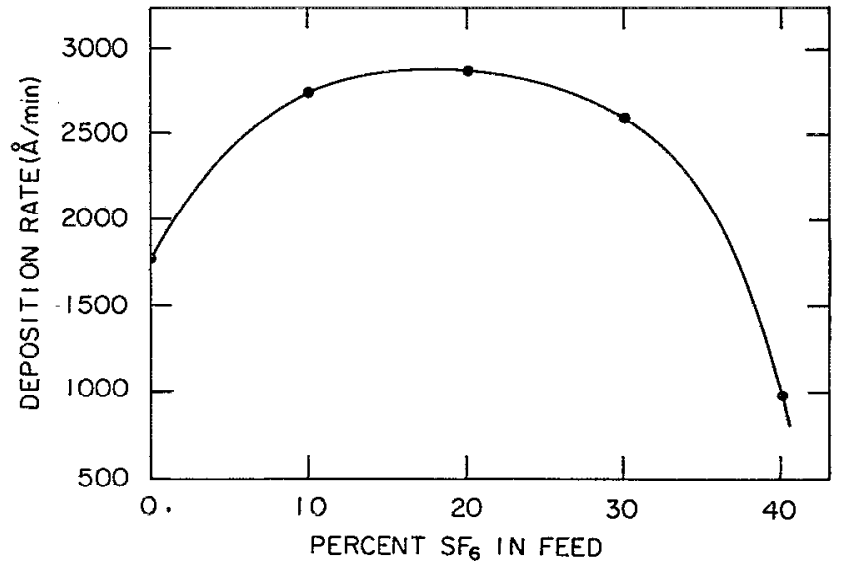

FIG. 7. Deposition rate as a function of the percent $\mathrm{SF}_{6}$ in the fecd.

served in the plasma (Fig. 3). Assuming that $\mathrm{CH}$ species are continuously attached to the growing polymer film, as are $\mathrm{CF}$ and $\mathrm{CF}_{2}$, a possible explanation for the small hydrogen content of the films at higher $\mathbf{S F}_{6}$ levels could be preferential detachment of $\mathbf{H}$ from the surface by the impacting electrons from the plasma. The detached $\mathbf{H}$ atoms may leave active sites in the surface that are then quenched by other species from the plasma, including the very active fluorine atoms.

Figure 7 shows the deposition rate of the polymer films obtained in $\mathrm{C}_{2} \mathrm{H}_{2}-\mathrm{SF}_{6}$ discharges as a function of the proportion of $\mathrm{SF}_{6}$ in the feed. As shown in this figure, pure $\mathrm{C}_{2} \mathrm{H}_{2}$ polymerizes rapidly, at a rate of about 1750 $\AA \min ^{-1}$. For $\mathrm{SF}_{6}$ levels exceeding about $40 \%$, the deposition rate becomes very small, probably because of the etching effect of atomic fluorine from the plasma. Actually we have observed that for $50 \% \mathrm{SF}_{6}$ in the feed, no polymer film is deposited. It is interesting to note, however, that for $\mathrm{SF}_{6}$ levels between $0 \%$ and about $37 \%$ the deposition rate is higher than $1750 \AA \min ^{-1}$.

The deposition rate of a plasma polymer depends upon the competition between polymerization and ablation; the latter includes etching by chemically active species from the discharge, and even sputtering, depending on the potential of the substrate with respect to that of the plasma. In $\mathrm{C}_{2} \mathrm{H}_{2}-\mathrm{SF}_{6}$ discharges, the etching mechanism is expected to be particularly active, due to the presence of atomic fluorine.

In order to interpret the results of Fig. 7, it should be remembercd that the electrons in the plasma, besides contributing to the generation of the true monomers and the etching species via gas-phase collisions, may also produce active sites by collisions with the polymer surface, thereby enhancing polymer growth. The activation of polymer sites by energetic electron or ion collisions is the basic mechanism of the activated growth mode (AGM), extensively investigated by d'Agostino et al. ${ }^{9,10,22}$ For low $\mathrm{SF}_{6}$ levels, ablation is still small and the increase in the deposition rate can be attributed to an increasing concentration of monomers in the gas phase and/or to an increasing activation of polymer surface sites. Since the levels of $\mathrm{CF}_{x}$ species rise 


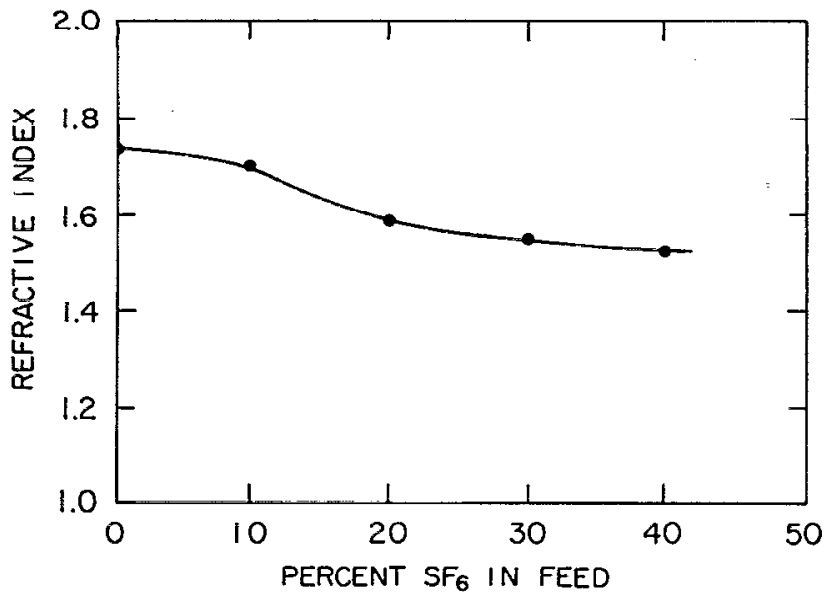

FIG. 8. The refractive index of the deposited films as a function of the percent $\mathrm{SF}_{6}$ in the feed.

with the addition of $\mathrm{SF}_{6}$ and $\mathrm{CH}$ (and possibly $\mathrm{CH}_{2}$ ) concentrations decrease, no conclusion can be drawn as to the overall increase in the concentration of monomers. However, an increase in the activation of polymer sites is very likely, since our data indicate that the average electron kinetic energy is higher at greater proportions of $\mathrm{SF}_{6}$. Indeed, we can show that in the whole range of the measurements, the behavior of the deposition rate is quite consistent with the AGM.

From Fig. 4 it can be appreciated that the ablation of the polymer film due to etching by $F$ atoms rises with the proportion of $\mathrm{SF}_{6}$ and reaches a maximum where there is about $28 \% \mathrm{SF}_{6}$ in the feed; thereafter it declines a little. On the other hand, Fig. 3 shows that the supply of $\mathrm{CF}_{x}$ monomers rises continually with the addition of $\mathrm{SF}_{6}$. Thus, the fact that the deposition rate does not increase for $\mathrm{SF}_{6}$ levels higher than about $28 \%$, exhibiting instead a sharp decrease, can immediately be explained as due to the decrease in the density of the electrons with an energy large enough to promote the activation of polymer sites. In fact, as indicated by the helium excitation efficiency curve of Fig. 2, for $\mathrm{SF}_{6}$ levels above $30 \%$, the average electron energies become even smaller than in pure $\mathrm{C}_{2} \mathrm{H}_{2}$ feeds.

\section{Optical properties}

The refractive index and the optical-absorption coefficient have been determined for various films obtained from discharges in $\mathrm{C}_{2} \mathrm{H}_{2}-\mathrm{SF}_{6}$ mixtures. The calculations were made from the data of the uv-visible transmission spectra.

The values of the refractive index for a photon energy of $1 \mathrm{eV}$ were determined by a procedure given by Cisneros et $a l_{.}^{23}$ and are plotted in Fig. 8 as a function of the percent of $\mathrm{SF}_{6}$ in the feed. For a feed of $100 \% \mathrm{C}_{2} \mathrm{H}_{2}$ the value of the refractive index (1.73) lies in the range of values for plasma-polymerized $\mathrm{C}_{2} \mathrm{H}_{2}$ films $(1.7-2.0)$ obtained by other investigators. ${ }^{24}$ The refractive index monotonically decreases from 1.73 to 1.56 as the proportion of $\mathrm{SF}_{6}$ in the
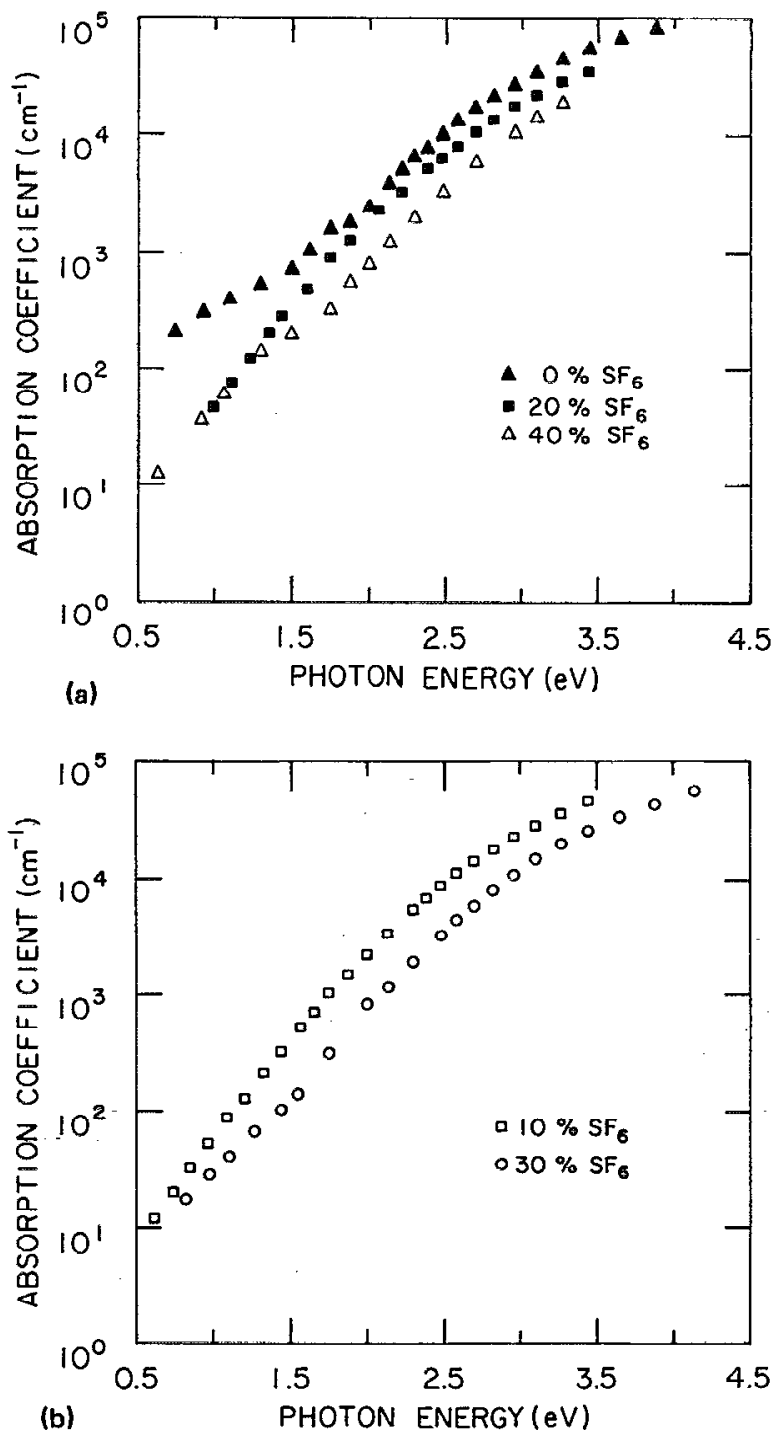

FIG. 9. (a) and (b) The optical-absorption coefficient of the deposited films as a function of the photon energy.

feed rises from $0 \%$ to $40 \%$. Thus the replacement of $\mathrm{C}-\mathrm{H}$ by $\mathrm{C}-\mathrm{F}$ bonds in the polymer films decreases the refractive index.

For the computation of the absorption coefficients, the following equation for the transmission has been used:

$$
T=A x /\left(B x^{2}+C x+D\right),
$$

where $x=\exp (\alpha d), \alpha$ and $d$ are the absorption coefficient and the thickness of the film respectively; $A, B, C$, and $D$ are functions of the optical properties of the film and substrate, as given in the Appendix. Equation (5) is rewritten from an expression given by Knittl ${ }^{25}$ for a thin film deposited onto a weakly absorbing substrate. Coherent multiple reflections in the thick substrate are considered in the derivation. As $A, B, C$, and $D$ depend weakly on $\alpha$ an iterative calculation of $\alpha$ converges rapidly.

Figure 9 illustrates the dependence of the optical-absorption coefficient on the photon energy for various films. In all the samples $\alpha$ rises sharply, showing an absorption edge similar to other noncrystalline materials such as 


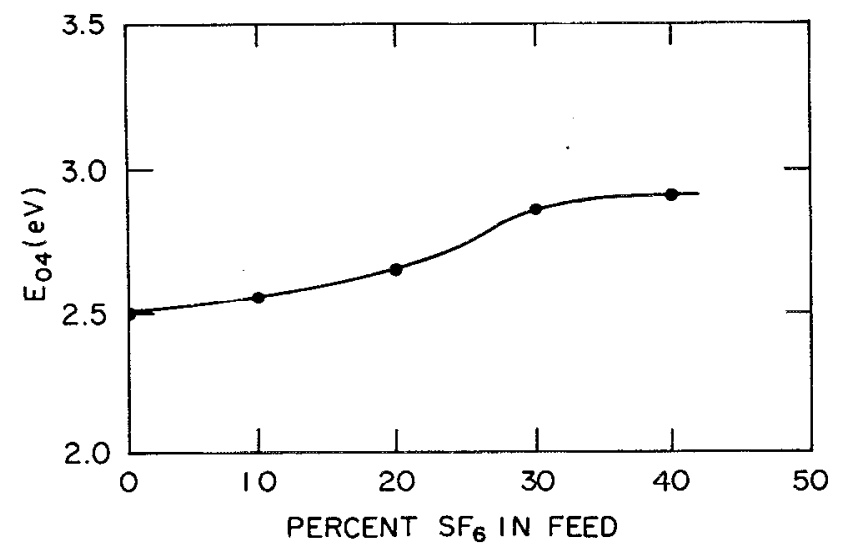

FIG. 10. The optical gap $E_{04}$ as a function of the percent $\mathrm{SF}_{6}$ in the feed.

amorphous hydrogenated semiconductors ${ }^{26}$ and amorphous hydrogenated carbon. ${ }^{27}$ Absorption is very low in the low-energy region. At $0.5 \mathrm{eV}$ the absorption coefficient for the film obtained in a $100 \% \mathrm{C}_{2} \mathrm{H}_{2}$ discharge is about $120 \mathrm{~cm}^{-1}$. The values of $\alpha$ at $0.5 \mathrm{eV}$ for our fluorinecontaining films $\left(7-9 \mathrm{~cm}^{-1}\right)$ are slightly below the value obtained at this energy by Dischler, Bubenzer, and Koid1 ${ }^{28}$ $\left(\alpha \approx 10 \mathrm{~cm}^{-1}\right)$ in hydrogenated amorphous carbon films prepared in rf discharges of benzene and deposited onto negatively biased substrates. Such films may find application as protective antireflecting coatings of very low absorption in the mid-ir region.

Differences in the optical absorption of materials can be characterized by an optical gap. For our samples we define as an optical gap the photon energy $E_{04}$ corresponding to the absorption at $\alpha=10^{4} \mathrm{~cm}^{-1}$. This procedure has already been used by Freeman and $\mathrm{Paul}^{29}$ to characterize the absorption edge of amorphous semiconductors. Figure 10 shows a plot of the values of the gap $E_{04}$ obtained from the absorption curves of Fig. 9, as a function of the proportion of $\mathrm{SF}_{6}$ in the feed. The values of $E_{04}$ increase from 2.5 to $2.8 \mathrm{eV}$ as the proportion of $\mathrm{SF}_{6}$ is raised from $0 \%$ to $40 \%$. It should be remembered that in many amorphous materials absorption can be described by the well-known Tauc model, ${ }^{30}$ according to which

$$
(\alpha E)^{1 / 2}=B\left(E-E_{g}\right),
$$

where $E_{g}$ is the optical gap and $B$ is a constant. Since the optical data of our samples did not reveal a linear relationship between $(\alpha E)^{1 / 2}$ and $E$, the optical gap could not be determined by Eq. (6).

The random structure of the carbon chains in a plasma polymer makes theoretical interpretation of the experimental results rather difficult. However, it seems reasonable to suppose that some trends in the physical behavior of a "conventional" polymer must be followed by a plasma polymer. In conjugated polymers, for instance, the $\pi$ bonds play a very important role in electronic conduction, affecting the density of states and the band gap. The density of $\pi$ bonds is influenced by the hydrogen content. Hydrogen forms $\sigma$ bonds with the carbon atoms at the expense of $\pi$ bonds. At the same time the attachment of hydrogen to the polymer affects bond lengths thus changing the band gap. The effect of fluorine is similar in that it forms $\sigma$ bonds with carbon and decreases the number of $\pi$ bonds. ${ }^{31}$ Owing to the high electronegativity of fluorine, the modifications in bond lengths are more pronounced than those caused by hydrogen attachment. This might explain why the absorption in our polymers decreased as the $\mathrm{C}-\mathrm{H}$ bonds were replaced by $\mathrm{C}-\mathrm{F}$ bonds.

\section{CONCLUSIONS}

Fluorinated organic films were deposited from $\mathrm{C}_{2} \mathrm{H}_{2}-\mathrm{SF}_{6}$ discharges. The composition of both plasma and deposited material were studied to understand the deposition process.

From trends in the emission intensities of the actinometers $\left(\mathrm{N}_{2}, \mathrm{Ar}, \mathrm{He}\right)$, a consistent picture of the EDF could be drawn. Our data strongly indicated that an increase in the proportion of $\mathrm{SF}_{6}$ to $\mathrm{C}_{2} \mathrm{H}_{2}$ in the discharge increased the average electron energy. Such an increase was assumed to contribute to the rapid rise in $\mathrm{CF}_{x}$ and $\mathrm{H}$ species concentrations.

Gas-phase $\mathrm{CF}, \mathrm{CF}_{2}$, and $\mathrm{CH}$ were considered as the true monomers of polymer formation even though the concentration of $\mathrm{CH}$ decreased with increasing $\mathrm{SF}_{6}$ levels. Probably the $\mathrm{CH}_{2}$ species also contributed to the growth of the polymer even though it was not observed.

Composition of the films was found to depend strongly on the proportion of $\mathrm{SF}_{6}$ to $\mathrm{C}_{2} \mathrm{H}_{2}$ in the discharge. At $40 \%$ $\mathrm{SF}_{6}$ in the feed, the fluorine content approached a maximum value, while the hydrogen content virtually disappeared.

The deposition rate of the polymer films was interpreted as a balance between polymer formation on the substrate and polymer ablation; the latter being a consequence of the etching effect of atomic fluorine generated in the discharge. Variation in the deposition rate as a function of the proportion of $\mathrm{SF}_{6}$ in the feed strongly indicated that the activated growth model applies to our films.

The optical properties of the films were found to depend on the fluorine content. As the $\mathrm{SF}_{6}$ level rose in the discharge (and consequently, the fluorine content of the film increased) the refractive index decreased while the optical gap increased.

The lack of theoretical models for plasma polymers does not allow detailed insight into the electronic structure of these materials. Some qualitative understanding, however, seems to be possible in view of some theoretical results already obtained for "conventional" polymers.

\section{ACKNOWLEDGMENTS}

We thank FAPESP, FINEP, and FAP of UNICAMP for financial support. Thanks are also due to Carlos $S$. Lambert for technical assistance, and Professor J. H. D. Silva, Professor D. Galvão, and Professor J. I. Cisneros for valuable discussions conccrning the optical measurements. 


\section{APPENDIX}

The functions $A, B, C$, and $D$ of Eq. (5) are given by

$$
\begin{aligned}
A= & 16 n_{s}\left(1-\rho_{s}\right)\left(n^{2}+k^{2}\right) U, \\
B= & s t-\rho_{s}(s v) U^{2}, \\
C= & 2\left(4 n_{s} k^{2}-Z Y\right) \cos \phi+4 k^{2}\left(Z+n_{s} Y\right) \\
& \times \sin \phi-\rho_{s} U^{2}\left[4 k\left(Z-n_{s} Y\right)\right. \\
& \left.\times \sin \phi-2\left(Z Y+4 n_{s} k^{2}\right) \cos \phi\right], \\
D= & u v-\rho_{s}(t u) U^{2},
\end{aligned}
$$

where $n_{s}$ and $n$ are the refractive index of the substrate and film, respectively, and $k$ is the extinction coefficient. The other variables are defined as follows:

$\rho_{s}=\left[\left(1-n_{s}\right) /\left(1+n_{s}\right)\right]^{2}, \quad \phi=4 \pi n h / \lambda$,

$U=\exp \left(-\alpha_{s} d\right), \quad s=(1+n)^{2}+k^{2}, \quad t=\left(n+n_{s}\right)^{2}+k^{2}$,

$u=(1-n)^{2}+k^{2}, \quad v=\left(n-n_{s}\right)^{2}+k^{2}, \quad Y=n^{2}+k^{2}-1$,

$Z=n^{2}+k^{2}-n_{s}^{2}$

where $\lambda$ is the wavelength of the incident light (in vacuum), $\alpha_{s}$ is the absorption coefficient of the substrate, and $h$ and $d$ are the thicknesses of the film and substrate, respectively.

${ }^{1}$ N. Inagaki, K. Suzuki, and K. Nejigaki, J. Polym. Sci. Polym. Lett. Ed. 21, 353 (1983).

${ }^{2}$ Y. Osada and M. Takase, J. Polym. Sci. Polym. Chem. Ed. 23, 2425 (1985).

${ }^{3}$ M. Hori, H. Yamada, T. Yoneda, S. Morita, and S. Hattori, J. Electrochem. Soc. 134, 707 (1987).

${ }^{4}$ P. Schreiber, M. B. Wertheimer, and A. M. Wrobel, Thin Solid Films 72,487 (1980).

5J. W. Coburn and M. Chen, J. Appl. Phys. 51, 3134 (1980).

${ }^{6} J$. W. Coburn and M. Chen, J. Vac. Sci. Technol. 18, 353 (1981).

${ }^{7}$ C. J. Mogab, A. C. Adams, and D. L. Flamm, J. Appl. Phys, 49, 3796 (1978).
${ }^{8}$ V. M. Donnelly, D. L. Flamm, W. C. Dautremont-Sinth, and D. J. Werder, J. Appl. Phys. 55, 242 (1984).

${ }^{9}$ R. d'Agostino, F. Cramarossa, V. Colaprico, and R. d'Ettole, J. Appl. Phys. 54, 1284 (1983).

${ }^{10}$ R. d'Agostino, F. Cramarossa, and F. Illuzzi, J. Appl. Phys. 61, 2754 (1987).

${ }^{11}$ D. E. Ibbotson, D. L. Flamm, and V. M. Donnelly, J. Appl. Phys. 54, 5974 (1983).

${ }^{12}$ R. A. Gottscho and T. A. Miller, Pure Appl. Chem. 56, 189 (1984).

${ }^{13}$ R. W. Dreyfus, J. M. Jasinski, R. E. Walkup, and G. S. Selwyn, Pure Appl. Chem, 57, 1265 (1985).

${ }^{14}$ R. d'Agostino, F. Cramarossa, S. De Benedictis, and G. Ferraro, J. Appl. Phys. 52, 1259 (1981).

${ }^{15}$ T. E. Madey and J. T. Yates, Jr., J. Vac. Sci. Technol. 8, 525 (1971); S. V. Pepper, J. Appl. Phys, 45, 4947 (1974).

${ }^{16}$ K. R. Ryan and I. C. Plumb, Plasma Chem. Plasma Process. 10, 207 (1990).

${ }^{17}$ K. R. Ryan and I. C. Plumb, The 9th International Symposium on Plasma Chemistry (IUPAC) ISPC-9, Pugnochiuso, Italy, edited by R. d'Agostino (IUPAC, Pugnochiuso, 1989), Vol. 2, p. 972.

${ }^{18}$ N. Sadeghi, H. Debontride, G. Turban, and M. C. Peignon, Plasma Chem. Plasma Process. 10, 553 (1990).

${ }^{19}$ N. Morosoff, B. Crist, M. Bumgarner, T. Hsu, and H. Yasuda, J. Macromol. Sci. Chem. A 10, 451 (1976).

${ }^{20}$ H. Yasuda, M. O. Bumgarner, H. C. Marsh, and N. Morosoff, J. Polym. Sci. Polym. Chem. Ed. 14, 195 (1976).

${ }^{21}$ W. A. Lanford and M. J. Rand, J. Appl. Phys. 49, 2473 (1978).

${ }^{22}$ R. d'Agostino, F. Cramarossa, F. Fracassi, E. Desimoni, L. Sabbatini, R. G. Zambonin, and G. Caporiccio, Thin Solid Films 143, 163 (1986).

${ }^{23}$ J. I, Cistreros, G. B. Rego, M. Tumyiama, S. Bilac, J. M. Gonçalves, A. E. Rodriguez, and Z. P. Arguello, Thin Solid Films 100, 155 (1983).

${ }^{24}$ D. R. McKenzie, R. C. McPhedran, and N. Savvides, Philos. Mag. 48, 341 (1983).

${ }^{25}$ Z. Knittl, Optics of Thin Films (Wiley, New York, 1976).

${ }^{26}$ G. D. Cody, in Semiconductors and Semimetals, edited by R. K. W. Willardson and A. C. Beer (Academic, New York, 1984), Vol. 21B, Chap. 2.

${ }^{27}$ F. W. Snith, J. Appl. Phys. 55, 764 (1984).

${ }^{28}$ B. Dischler, A. Bubenzer, and P. Koidl, Appl. Phys. Lett. 42, 636 (1983).

${ }^{29}$ E. C. Freeman and W. Paul, Phys. Rev. B 20, 716 (1979).

${ }^{30} \mathrm{~J}$. Tauc, in Optical Properties of Solids, edited by F. Abeles (NorthHolland, Amsterdam, 1972), Chap. 5.

${ }^{31}$ A. K. Bakhshi, J. Ladik, and C. M. Liegener, Synth. Met. 20, 43 (1987). 